Technological University Dublin

DÜBLIN

ARROW@TU Dublin

2007-01-01

\title{
Comparative Evaluation of two Models of UPQC for Suitable Interface to Enhance Power Quality
}

\author{
Malabika Basu \\ Technological University Dublin, mbasu@tudublin.ie \\ S. P. Das \\ Indian Institute of Technology - Kanpur \\ Gopal Dubey \\ Indian Institute of Technology - Kanpur
}

Follow this and additional works at: https://arrow.tudublin.ie/engscheleart2

Part of the Electrical and Computer Engineering Commons

\section{Recommended Citation}

Basu, M., Das, S., Dubey, G.: Comparative evaluation of two models of UPQC for suitable interface to enhance power quality. Electric Power Systems Research, Vol. 77, no. 7, pp.821-830. 2007. doi:10.1016/ j.epsr.2006.07.008

This Article is brought to you for free and open access by the School of Electrical and Electronic Engineering at ARROW@TU Dublin. It has been accepted for inclusion in Articles by an authorized administrator of ARROW@TU Dublin. For more information, please contact arrow.admin@tudublin.ie, aisling.coyne@tudublin.ie, gerard.connolly@tudublin.ie.

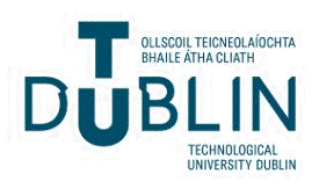




\title{
Comparative Evaluation of Two Models of UPQC for Suitable Interface to Enhance Power Quality
}

\author{
Malabika Basu $^{1 *} \quad$ Shyama P. Das ${ }^{2} \quad$ Gopal K. Dubey
}

1. Dept of Electrical Engg

Dublin Institute of Technology,

Kevin Street, Dublin -8, Ireland

Email: mbasu@dit.ie

* corresponding author

2. Dept of Electrical Engineering

Indian Institute of Technology, Kanpur

India

\begin{abstract}
:
Majority of the dispersed generations from renewable energy sources are connected to the grid through power electronic interface, which introduce additional harmonics in the distribution systems. Research is being carried out to integrate active filtering with specific interface such that a common power quality (PQ) platform could be achieved. For generalized solution, a unified power quality conditioner (UPQC) could be the most comprehensive PQ protecting device for sensitive non-linear loads, which require quality input supply. Also, load current harmonic isolation needs to be ensured for maintaining the quality of the supply current.

The present paper describes two control scheme models for UPQC, for enhancing PQ of sensitive non-linear loads. Based on two different kinds of voltage compensation strategy, two control schemes have been designed, which are termed as UPQC-Q and UPQC-P. A comparative loading analysis has developed useful insight in finding the typical application of the two different control schemes. The effectiveness of the two control schemes is verified through extensive simulation using the software SABER. As the power circuit configuration of UPQC remains same for both the models, with modification of control scheme only, the utility of UPQC can be optimized depending upon the application requirement.
\end{abstract}

Key words:

Distributed generation, power quality, VA rating analysis, UPQC 


\section{Comparative Evaluation of Two Models of UPQC for Enhancing Power Quality}

\section{INTRODUCTION}

Distributed generation (DG) systems have both advantages and disadvantages in relation to grid power quality (PQ). They can increase the efficiency of systems by local power generation. More reliable and uninterrupted power can be provided to customers, with energy cost savings [1]. World wide DG penetration in the grid is on the rising. For example, Denmark has a high penetration of wind energy in the country with $14 \%$ of the whole electrical energy consumption supplied from wind [2]. A study by EPRI indicates that by $2010,25 \%$ of new generation will be DG and at least it will be $20 \%$ of the total electrical utility market, worth of USD 72 billion.[3] Deregulation of electricity market may contribute to rising penetration level of DG from renewable energy sources (wind, solar, biomass etc) in the near future[4]. From the perspective of environmental protection, DG from renewable energy sources is of great importance, as they minimize harmful emissions. As most of the DG systems are interfaced to the grid through power electronic interface, hence injection of additional higher frequency harmonics in the system is obvious. Therefore, additional grid integration problems are equally worrying from electrical pollution point of view if not attended properly. Furthermore, variable wind speed, variation in solar and tidal power etc are uncontrollable parameters which are bound to affect the generated power quality.

Research is being carried out to integrate active filtering options into the integrating power electronic converters themselves $[2,5]$, but they need to be case specific. From the perspective of 
sensitive non-linear loads in the distribution system, a common platform of PQ needs to be ensured; as PQ varies due to various types of sources of generation. Hence, suitable power conditioning interfaces are recommended for sensitive non-linear loads. These type of loads primarily include production industries (like automotive plants, paper mills, chemical and pharmaceutical industries, semiconductor manufacturing plants etc), and critical service providers like medical centres, airports, broadcasting centres etc. Typical grid integration problems associate with voltage and frequency compatibility and requirement of active and reactive power. A power conditioning equipment can act as an interface between the grid and sensitive loads, so that the load can remain insensitive to the variation of power quality from the utility. Unified Power Quality Conditioner (UPQC) happens to be the most comprehensive power conditioning equipment that can mitigate both voltage and current quality problems $[6,7]$.

In this paper two models of UPQC are discussed and analysed from the perspective of VA loading and applications. Functionally UPQC is a combination of series and shunt active filter, for maintaining desired quality of both the incoming voltage and current. But its coordinated control gives it unique feature in terms of shared responsibility and reduced VA rating as compared to individual dynamic voltage restorer (DVR) $[8,11]$ or active power filter (APF) $[6,9$, 11]. The two control schemes described in this paper have common current control strategy, which is based on hysteresis current control. The series voltage compensation can be performed in a number of ways, which are non unique. Based on the two extreme options, two control schemes have been designed and their performance and rating are analysed. The insight gained could be useful for design of control strategy of UPQC for various applications. 
The organization of the paper is as follows. In section II UPQC topology and power flow strategy is described. Section III describes the two proposed control strategies for UPQC for different applications. Section IV discusses analytically the VA loading and rating issues. Simulation results in support of the control strategy are provided in section V. Finally, the conclusions are presented in section VI.

\section{UPQC TOPOLOGY AND POWER FLOW STRATEGY}

A three-phase UPQC consists of two three-phase voltage source inverters connected in cascade as shown in Fig. 1. Inverter 1 (Series Inverter (SEI)) is connected in series with the incoming utility supply through a low pass filter and a voltage injecting transformer. Inverter 2 ( Shunt Inverter (SHI)) is connected in parallel with the sensitive load, whose power quality needs to be strictly maintained. The main purpose of SHI is to provide required VAR support to the load, and suppress the load current harmonics from flowing towards the utility and it is operated in current controlled mode. SEI is responsible for compensating the deficiency in voltage quality of the incoming supply, such that the load end voltage remains insensitive to the variation of utility supply. The two models of UPQC discussed in this paper have same power circuit configuration. But as the control strategies are different in SEI, the individual loading of SHI and SEI varies and the overall rating of the UPQC differs, which is the thrust of this paper and is explained in the subsequent sections. UPQC also have a few other important components that are essential for interfacing of the equipment.

- The $\mathrm{SHI}$ is connected through a boost inductor $\mathrm{L}_{\mathrm{SHI}}$, which can boost up the common de link voltage to the desired value through appropriate control. The size of the inductor L has to be chosen carefully, as increase in size would cause slower response to current control. 
- The de link capacitor C provides the common de link voltage to both SEI and SHI. Ideally once charged, the dc link voltage should not fall off its charge, but due to finite switching losses of the inverters, inductor and capacitor, some active power is consumed and the charge of the dc link voltage needs to be maintained in a closed loop control, through the SHI. The choice of the reference dc link voltage depends upon the percentage of voltage sag to be mitigated and amount of VAR to be shared. The higher of the two values is to be chosen to comply with all needs. It is to be noted that as the $\mathrm{C}$ is charged continuously through SHI, it does not require additional source of voltage support. The online charging also helps UPQC in mitigating voltage unbalance or under-voltage situations for longer durations, as it is not limited by the storage capacity of separate voltage source.

- The SEI needs to be connected to the supply side through a series injection transformer and a low pass filter (LPF), to eliminate the high switching frequency ripple of the inverter. The filter may inject some phase shift, which could be load dependent, but suitable feedback control is to be designed to dynamically adjust the shift, which is described in the control section.

The utility supply being the only source of active power, the source of active power flow through UPQC originates from the supply. But the reactive power and load harmonic currents are shared between the SHI and loads primarily. Therefore, SHI provides harmonic isolation to the utility. SEI may also share some VAR depending upon control, described further in the subsequent section. 


\section{CONTROL STRATEGIES}

In this section two control schemes of UPQC are discussed. As the SHI control scheme remains same in both the schemes, that is discussed first and then the two different SEI schemes are explained.

\section{Control scheme for SHI}

To ensure fast elimination of higher order current harmonics of the load, hysteresis controller is designed for controlling the switching of the SHI. Based on the active power demand of the load, a suitable sinusoidal reference is selected for the incoming utility current and in addition appropriate hysteresis band is selected. Narrower hysteresis band ensures higher THD elimination, at the cost of higher switching frequency of the inverter. Suitable trade off in design is required to optimize all criteria.

As discussed earlier, the dc link voltage ideally should not decay, unless some active power loss occurs in the UPQC. Therefore, the deviation of the dc link voltage acts as a measure of active power requirement from utility supply. The error is processed through a PI controller and a suitable sinusoidal reference signal in phase with the supply voltage is multiplied with the output of the PI controller, to generate the reference current for the supply. Hysteresis band is imposed on top and bottom of this reference current. The width of the hysteresis band is adjusted such that the supply current THD remains within international agencies specified limit. As the supply current hits the upper or lower band, appropriate switching of the SHI takes place so as to compel the supply current to remain within the band, by either aiding its de link voltage to utility supply or by opposing. 


\section{Control Scheme A (Quadrature compensation for SEI)[7]}

In this scheme the injected voltage from SEI maintains a Quadrature advance relationship with the supply current, so no real power is consumed by SEI in the steady state. This is a significant advantage when UPQC mitigates under-voltage conditions. The SEI also shares the VAR of the load along with SHI, so the VA loading of SHI reduces. To highlight this aspect of quadrature voltage injection, this scheme will be henceforth addressed as UPQC-Q.

Fig. 2 shows the current and voltage required from UPQC under a typical load power factor condition for a typical voltage sag. When the supply voltage has no deficiency; $V_{S}=V_{L I}=V_{S I}=$ $V_{0}$ (a constant), and the series injected voltage $\mathrm{V}_{\text {inj }}$ requirement is zero.This state is represented by adding suffix "1" to all the voltage and current quantities of interest. The load current is $\mathrm{I}_{\mathrm{L} 1}$ $\left(\mathrm{I}_{\mathrm{L} 1}=\mathrm{I}_{\mathrm{L}}\right)$ and the SHI compensates the reactive component $\mathrm{I}_{\mathrm{C1}}$ of the load, resulting in unity power factor. Thus, the current drawn by the $\mathrm{SHI}$ is $-\mathrm{I}_{\mathrm{Cl}}$, which is opposite to the load reactive current $I_{C 1}$. As a result, the load always draws the in-phase component $I_{S 1}$ from the supply. For nonlinear loads, the SHI not only supplies the reactive current, but also the harmonic currents required for the load. Thus, after the compensation action of the SHI, only the fundamental active component of the current is required to be supplied from the utility. Since the SHI is able to compensate load VAR and harmonics, the SEI can compensate the voltage sag. As soon as the load voltage $\mathrm{V}_{\mathrm{L}}$ sags, due to utility voltage problems, the UPQC is required to take action to compensate for the sag, so that $\mathrm{V}_{\mathrm{L}}$ is restored to its desired magnitude. As seen from fig. 2, the restoration of $V_{L}$ is achieved by specifically selecting $\gamma=90^{\circ}$. This condition is represented by adding suffix " 2 " to the parameters. Consequently the load current changes to $\mathrm{I}_{\mathrm{L} 2}$. The SHI injects $I_{\mathrm{C} 2}$ in such a way that the active power requirement of the load is only drawn from the utility. Therefore, from the utility side the load power factor is always unity. It can be observed

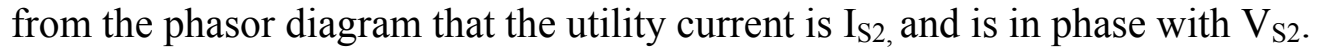

If the active power demand is constant,

$$
\mathrm{V}_{\mathrm{S} 1} \cdot \mathrm{I}_{\mathrm{S} 1}=\mathrm{V}_{\mathrm{S} 2} \cdot \mathrm{I}_{\mathrm{S} 2}
$$

which can be written as 


$$
I_{S 2}=\frac{V_{S 1} I_{S 1}}{V_{S 2}}
$$

Between the control loops, the hysteresis current control loop used with the SHI is much faster than the voltage control loop of the SEI. The two loop speeds are chosen such that in no case these two controllers can interfere with each other and cause instability.

Fig. 3 gives an overview of the control schematic for the UPQC-Q. The supply voltage peak detector would indicate of any voltage sag, which would require to be compensated by the SEI of UPQC-Q. One fast feed-forward path is designed to determine the initial modulating index of the SEI. A slower feedback path through another PI controller is implemented to nullify the injected phase angle error, which may occur due to dynamic load change and the presence of LPF. Because of quadrature voltage injection by SEI, the Low Pass Filter (LPF), load current will appear to be inductive to the SEI and significant variation in the load current would alter the phase angle that cannot be predetermined. But a feedback controller that compares the actual injected voltage (Vinj) to the ideal injected voltage (Vinj*) can eliminate this error caused due to dynamic load change.

Apart from these, there are transformer leakage reactance drop, resistance drop and the voltage drop due to the Low Pass Filter (LPF) connected at the output of the SEI to filter the switching ripples of the SEI. The load power increase (active current increase) leads to increase in the source current. This current is also reflected in the primary side of the series transformer. Thus the drop in the above mentioned elements change the injected voltage magnitude and phase which need to be corrected by a closed-loop control with good dynamics. It should be noted that only open-loop control for the SEI is inadequate. 


\section{Control Scheme B for SEI [10]}

In this scheme, in general the injected voltage is in phase with the supply voltage when the supply is balanced. Therefore mostly the SEI would consume active power. To distinguish from the earlier SEI control scheme this type of UPQC control scheme will be henceforth addressed as UPQC-P. By virtue of in phase injection, UPQC-P will mitigate voltage sag conditions by minimum injected voltage. The phasor diagram of Fig. 4 explains the operation of UPQC-P for the fundamental frequency. When the system voltage and current are in phase due to the action of the shunt compensator, the series converter handles purely active power. As seen from Fig. 4, the SHI current increases when there is a supply voltage sag, as the SEI consumes active power through the SHI. When the supply sag is created, the SEI of the UPQC-P should compensate for the fall in voltage to maintain the load voltage to its specified value. The injected voltage being in-phase with the supply voltage, the supply current and injected voltages are also in-phase with each other. Hence, the SEI handles only active power. The SEI delivers this additional active power by drawing the same from the dc link of the UPQC-P. Therefore, it acts as an active load to the $\mathrm{SHI}$. As seen from the phasor diagram, $\mathrm{I}_{\mathrm{C} 2}$ has an additional active and same reactive component as $\mathrm{I}_{\mathrm{C} 1}$.

The control scheme is based on abc-dqo analysis of the incoming voltage. In steady state and balanced supply voltage condition, the d- component of voltage will be $396.7 \mathrm{~V}$ dc for $230 \mathrm{~V}$ rms phase voltage, which is considered as reference. The $\mathrm{q}$ and o-component of voltage will be zero. If there is a balanced supply voltage sag, the $d$ component of voltage will deviate from the reference voltage, but $\mathrm{q}$ and o-component will remain zero. In case of unbalanced supply voltage sag $\mathrm{q}$ and o-components will be ac quantities and d-component of voltage will contain both dc and ac quantities. The ideal reference being known the SEI would operate in such a 
manner so that the difference in voltage between the reference d-q-o quantities and the actual quantities are supplied by SEI. A closed loop feedback can ensure the dynamical changes are taken care of. Fig. 5 shows the detail of the SEI control scheme for UPQC-P.

\section{COMPARATIVE VA RATING CALCULATION AND ANALYSIS} $U P Q C-Q$

The overall VA handled by the UPQC is an important factor deciding its size. The power loss is also related to the VA loading of the UPQC. Here, the loading calculation has been carried out on the basis of linear load for fundamental frequency [10]. From Fig. 2 it can be found out that the load voltage is to be kept constant at $V_{\text {o }}$ p.u. irrespective of the supply voltage variation.

$V_{S}=V_{L 1}=V_{L 2}=V_{S l}=V_{o} p \cdot u$.

The load current is assumed to be constant at the rated value, i.e.,

$I_{L}=I_{L 1}=I_{L 2}=I_{o} p \cdot u$,

with fundamental p.f. $=\cos \phi$. Assuming the UPQC-Q to be lossless, the active power demand in the load remains constant and is drawn from the source, i.e.

$\mathrm{V}_{\mathrm{S}} \mathrm{I}_{\mathrm{S}}=\mathrm{V}_{\mathrm{L}} \mathrm{I}_{\mathrm{L}} \cos \phi$

In case of a sag when $\mathrm{V}_{\mathrm{S} 2}<\mathrm{V}_{\mathrm{S} 1}$, where $\mathrm{x}$ denotes the p.u. sag,

$V_{S 2}=(1-x) V_{S 1}=V_{o}(1-x) p \cdot u$.

Now, to maintain constant active power under the voltage sag condition, (as explained in (1),

$I_{S 2}=\left(V_{S I} \cdot I_{L} \cos \phi\right) / V_{S 1} \cdot(1-x)=I_{o} \cos \phi /(1-x) p \cdot u$.

As the voltage injected $\left(\mathrm{V}_{\text {inj }}\right)$ by the SEI is in quadrature with the supply, the resultant load voltage $\mathrm{V}_{\mathrm{L} 2}$ makes an angle $\theta$ (Fig. 2) with the supply $\mathrm{V}_{\mathrm{S} 2}$, which implies

$$
V_{i n j}=\sqrt{\left(V_{S l}^{2}-V_{S 2}^{2}\right)}
$$


$\therefore \frac{V_{i n j}}{V_{S 2}}=\tan \theta, V_{i n j}=V_{S 2} \tan \theta, V_{i n j}=V_{o}(1-x) \tan \theta \quad$ p.u.

$\therefore$ SEI VA Rating $=V_{i n j .} I_{S 2}=V_{o} I_{o} \cos \phi \tan \theta \quad$ p.u.

The SHI current can be calculated from the trigonometry of the vector diagram (fig.2)

$$
\begin{aligned}
& I_{c 2}=\sqrt{I_{L 2}^{2}+I_{s 2}^{2}-2 I_{L 2} I_{s 2} \cos (\phi-\theta)} \\
& =I_{o} \frac{\sqrt{(1-x)^{2}+\cos ^{2} \phi-2 \cos \phi \cos (\phi-\theta)(1-x)}}{(1-x)} \text { p.u. }
\end{aligned}
$$

It follows that the rating of the SHI is

$$
\begin{aligned}
\mathrm{V}_{\mathrm{L} 2} I_{c 2}= & \mathrm{V}_{\mathrm{o}} I_{o} \frac{\sqrt{(1-x)^{2}+\cos ^{2} \phi-2 \cos \phi \cos (\phi-\theta)(1-x)}}{(1-x)}+ \\
& I_{o}^{2} \frac{(1-\mathrm{x})^{2}+\cos ^{2} \phi-2 \cos \phi \cos (\phi-\theta)(1-\mathrm{x})}{(1-\mathrm{x})^{2}} Z_{S H I} \quad \text { p.u. }
\end{aligned}
$$

where $Z_{\mathrm{SHI}}$ is the shunt inductance impedance.Adding (9) and (11), the total VA rating of the UPQC-Q can be evaluated.

\section{UPQC-P}

The loading calculation of UPQC-P has been carried out on the basis of linear load.

From phasor diagram of Fig. 4, it can be found that for each phase

$V_{L 1}=V_{L 2}=V_{S 1}=V_{o}$ p.u.

If load current is assumed to be $I_{L}=I_{L 1}=I_{L 2}=I_{o}$ p.u,

with fundamental p.f. $=\cos \phi$, active power demand in the load remains the same,

i.e. $V_{S} I_{S}=V_{L} I_{L} \cos \phi$

In case of sag when $\mathrm{V}_{\mathrm{S} 2}<\mathrm{V}_{\mathrm{S} 1}, \quad$ where $\mathrm{x}$ denotes the p.u. sag,

$V_{S 2}=(1-x) V_{S 1}=V_{o}(1-x)$ p.u.

Now, to maintain constant active power 
$V_{S 1} I_{S 1}=V_{S 2} I_{S 2}$

Which leads to, $I_{S 2}=\left(V_{S 1} . I_{L} \cos \phi\right) / V_{S I .}(1-x)=I_{o} \cos \phi /(1-x) p . u$.

$\therefore$ SEI VA Rating $=V_{i n j} . I_{S 2}=V_{o} I_{o}(x \cdot \cos \phi) /(1-x) p \cdot u$.

and

$$
\begin{aligned}
I_{C 2} & =\sqrt{I_{L 1}^{2}+I_{s 2}^{2}-2 I_{L 1} I_{S 2} \cos \phi} \\
& =I_{o} \frac{\sqrt{(1-\mathrm{x})^{2}+\cos ^{2} \phi\{1-2(1-\mathrm{x})\}}}{(1-\mathrm{x})} \text { p.u. }
\end{aligned}
$$

$\therefore$ SHI VA Rating

$=\mathrm{V}_{\mathrm{o}} \mathrm{I}_{\mathrm{o}} \frac{1}{(1-x)} \sqrt{(1-x)^{2}+\cos ^{2} \phi\{1-2(1-x)\}}+\mathrm{I}_{\mathrm{o}}^{2} \frac{(1-x)^{2}+\cos ^{2} \phi\{1-2(1-x)\}}{(1-\mathrm{x})^{2}} Z_{\mathrm{SHI}}$ p.u.

Adding (18) and (20), the total VA rating of the UPQC-P is found .

\section{Comparative analysis of VA loading:}

Figs. 6-8 show the compariosn of SEI, SHI and total loading of UPQC respectively. The ten points in each set are for p.u. supply voltage sag from $5 \%$ to $50 \%$, which are typical. This range has been chosen as the most practical cases are observed to be in this range as available from PQ survey reports. A wide range of load power factor has been chosen from 0.6 lagging to unity power factor (u.p.f), with $Z_{\mathrm{SHI}}=1$ p.u. in all cases. The rating of the equipment has been estimated from (9and10). The maximum loading within the opearting zone would determine the rating of the individual inverter, and the summation of the two would yield the total rating of UPQC.

As observed from Fig. 6, it is seen that loading on the SEI increases as \% sag increases. The SEI maximum loading under UPQC-P control rating will be 1 p.u. (based on maximum loading at 
$50 \%$ sag at upf load p.f ) to successfully cater the mentioned region of voltage sag under the specified power factor variation. Corresponding UPQC-Q SEI loading is 1.73 p.u. From Fig. 7 it is observed that the maximum loading condition occurs at similar condition mentioned above. Maximum SHI for UPQC-P is 2 p.u., whereas for UPQC-Q it is as high as 4.73 p.u. The total VA loading is sum of the two individual loading, and thus maximum UPQC-P rating would be 3 p.u and UPQC-Q would be $6.46 \mathrm{pu}$.

It is interesting to note that UPQC-Q does not seem to be the natural choice considering the double rating as compared to UPQC-P. However, considering all the detail of the SHI loading curves in Fig. 7, it can be observed that the loading of SHI of the UPQC-Q is considerably lower than that of UPQC-P in the low power factor load region. Hence, depending upon the load requirement, UPQC-Q could be a better choice, where VAR demand of the load may be high, and typically the need for VAR compensation would be essential. Thus considering the application area of operation upto 0.8 lagging pf, and upto $50 \%$ supply voltage sag, typically with the same rating of UPQC-Q and UPQC-P around 2.8 p.u. (Fig. 8), the overall VA loading of UPQC-Q would be much smaller than UPQC-P. Hence, the associated losses of the equipment would be less and overall system efficiency would be higher.

There is another important observation in Fig. 7 which distinctly shows that the loading on the SHI is mutually related to the load power factor and \% voltage sag. For each power factor, certain percentage of sag creates zero loading condition of the SHI. From Fig. 2 it can be observed that for a typical load power factor condition and supply voltage sag, $\mathrm{I}_{\mathrm{C} 2}$ can reach zero value if $\theta=\phi$. Following this condition to minimize $I_{\mathrm{C} 2}$ w.r.t. $\mathrm{x}$ using (10), we get the relationship between voltage sag and the load power factor condition, which is given by

$$
x+\cos \phi=1
$$


If $\theta<\phi$, SHI and SEI share the VAR of the load. But if $\theta>\phi$, then SHI current has to increase with the opposite sign to bring back leading power factor to unity, and this increases the loading of the SHI additionally.

\section{SIMULATION RESULTS}

The analysis of UPQC control schemes has been extensively simulated in SABER software, which can implement extensive control schemes. A $400 \mathrm{~V}$ (L-L) three-phase three-wire system with nonlinear diode bridge rectifier load has been considered. Fig. 9 shows the typical three phase load currents and supply currents. It is seen clearly that the quasi square wave shapes of the load current, with high THD of $24 \%$ do not reflect the incoming supply current. The hysteresis controller of SHI has forced the input current to be sinusoidal and the THD has been brought down within 5\%. This control is equally effective in UPQC-P and UPQC-Q.

Fig. 10 explains the operation of UPQC-Q under $20 \%$ balanced supply voltage sag. The load voltage, supply voltage and injected voltage of phase A are plotted. The harmonic spectra of load voltage remain satisfactory (THD within 3.3\%). The injected voltage maintains a quadrature relationship with the supply voltage as per the control scheme and can be verified from Fig. 10.

Fig. 11 explains the operation of UPQC-P under $20 \%$ balanced supply voltage sag for a duration of $0.15 \mathrm{sec}$. There is an instantanesous undershoot at the instant of occurrence of sag around $14 \%$, which cannot be avoided.

The additional advantage of UPQC-P type control is that it can mitigate unbalanced voltage sag. Figs. 12 and 13 present the performance of UPQC-P for unbalanced voltage sag mitigation. In Fig. 12 it is found that at $\mathrm{t}=0.1 \mathrm{sec}$, the peak of three phase voltages become $300 \mathrm{~V}, 275 \mathrm{~V}$ and $250 \mathrm{~V}$ in phases $\mathrm{A} \mathrm{B}$ and $\mathrm{C}$ respectively. But the lower trace of load voltages are balanced 
and are maintained to the desired value of $230 \mathrm{~V}(\mathrm{rms})$ (325 V peak). From Fig. 16, it is found that when a supply voltage sag occurs, q-component voltage becomes ac peak to peak of $35 \mathrm{~V}$ with frequency $100 \mathrm{~Hz}$, o-component voltage becomes ac peak to peak of $50 \mathrm{~V}$ with frequency $100 \mathrm{~Hz}$. The d-component voltage is seen to be reduced by $60 \mathrm{~V}$ with a superimposed voltage ripple of $35 \mathrm{~V}$ (peak to peak, with frequency $100 \mathrm{~Hz}$ ).It is found that after series injection of voltage by UPQC, the load voltage harmonic spectra remain within IEEE specified limit of 5\% THD. Thus the simulation results show satisfactory performance of UPQC-P.

\section{CONCLUSION}

The present paper investigates the performance of UPQC as a suitable interfacing equipment for enhancement of power quality. Two control schemes have been analysed based on the different voltage compensation schemes of the SEI. UPQC-Q has the advantage of VAR sharing between the two compensators. The SEI, while injecting voltage to mitigate the supply voltage sag, shares a part of VAR of the load and does not consume any active power. But at higher power factor load $(>0.9)$, the loading requirement of UPQC-Q is quite high due to excessive high SHI rating. The SHI rating of the UPQC-Q increases at a higher rate to compensate the effective leading input power factor created by quadrature voltage injection. This shifts the load voltage angle, seen from the utility side. Therefore, for higher power factor loads UPQC-P rating would be substantially lower than that of UPQC-Q. Also UPQC-Q cannot compensate unbalanced voltage sag. But for applications where VAR demand is very high UPQC-Q could be a potential control scheme for action, as it can effectively reduce the input power factor angle seen from the utility side. 
The SEI control scheme of UPQC-P is based on $\mathrm{d}-\mathrm{q}-\mathrm{o}$ component analysis. UPQC-P can mitigate the supply voltage-unbalancing problem also besides voltage sag as the individual modulating signals can vary in phase because they would be directly derived from the d-q-o component analysis. Under balanced voltage sag condition, the load voltage angle after compensation is not altered. Therefore, the SHI of the UPQC-P does not require to compensate any additional VAR created due to SEI control action.

Comparative loading analysis has brought useful insight in finding the typical application of the two different control schemes. The effectiveness of the two control schemes is verified through extensive simulation in the software SABER. As the power circuit configuration of UPQC remains same in both models, with modification of control scheme only, the utility of UPQC can be optimized depending upon the application requirement.

\section{REFERENCES}

[1] K. Kowalenko, Distributed Power Offers an Alternative to Electric Utilities, Piscataway, NJ: IEEE Press, 2001, vol. 25.

[2] F. Blaabjerg, Z. Chen and S.B. Kjaer, "Power electronics as efficient interface in dispersed power generation systems", IEEE Trans. Power Electron., vol. 19, no. 5, Sep. 2004, pp. 1184-1194.

[3] F. Z. Peng, "Editorial: Special issue on distributed power generation", IEEE Trans. Power Electron., vol. 19, no. 5, Sep. 2004, pp. 1157-1158.

[4] T. S. Perry, "Deregulation may give a boost to renewable resources", IEEE Spectrum Jan. 2001, p. 87.

[5] K. J. P. Macken et al, "Distributed control of renewable generation units with integrated active filter”, IEEE Trans. Power Electron., vol. 19, no. 5, Sep. 2004, pp. 1353- 1360. 
[6] H. Fujita and H. Akagi, "The unified power quality conditioner: the integration of series and shunt active filters", IEEE Trans. Power Electron., vol. 13, no. 2, Mar. 1998, pp. 315322.

[7] M. Basu, S. P. Das and G. K. Dubey, "Performance study of UPQC-Q for load compensation and voltage sag mitigation," IEEE IECON 02, Sevilla, Spain, 5-8 November, 2002, pp. 698-703.

[8] S. S. Choi, B. H. Li, and D. M. Vilathgamuwa, "Dynamic voltage restoration with minimum energy injection," IEEE Transactions on Power Systems, vol. 15, no. 1, February 2000, pp. 51-57.

[9] K. Chatterjee, B. G. Fernandes, and G. K. Dubey, "An instantaneous reactive volt-ampere compensator and harmonic suppressor system," IEEE Trans. on Power Electronics, vol. 14, no. 2, March 1999, pp. 381-392.

[10] M. Basu, "Some investigations on unified power quality conditioner", Ph.D. dissertation, Dept. of Electrical Eng., IIT-Kanpur, India, 2003.

[11] N. G. Hingorani and L. Gyugyi, Understanding FACTS: Concepts and Technology of Flexible AC Transmission Systems, IEEE Press, 2001. 


\section{List of Figures}

Fig. 1. Configuration of UPQC

Fig. 2. Phasor diagram of UPQC with control scheme A

Fig. 3. Control scheme of UPQC-Q

Fig. 4. Phasor diagram of UPQC with control scheme B

Fig. 5. Control scheme of UPQC-P

Fig. 6. SEI VA rating

Fig. 7. SHI VA rating

Fig. 8. Total VA rating

Fig. 9. Three phase load and supply currents

Fig. 10. Load, supply and injected voltages of phase A, under normal and $20 \%$ supply sag condition

Fig. 11. Load voltage and supply voltage profile under normal and $20 \%$ balanced sag condition

Fig. 12. Load voltage and supply voltage profile under normal and unbalanced sag condition

Fig. 13. d- q-o component of voltage under balanced sag condition 


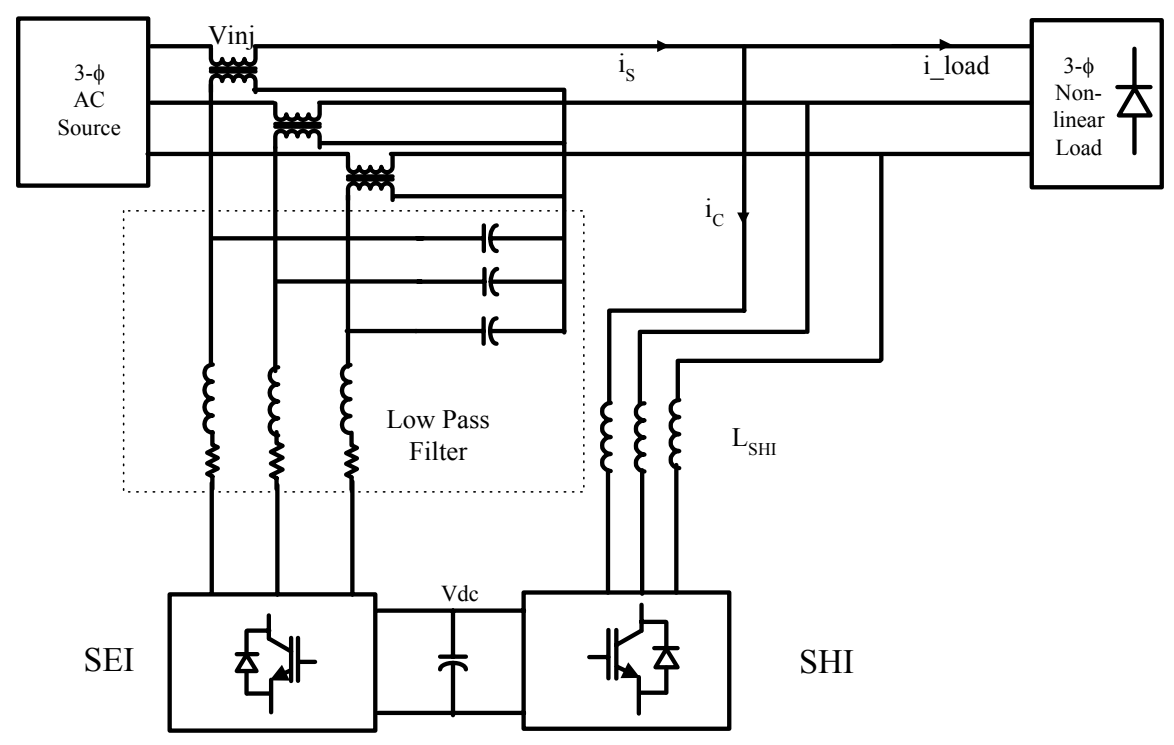

Fig 1. Power circuit diagram of three phase UPQC 

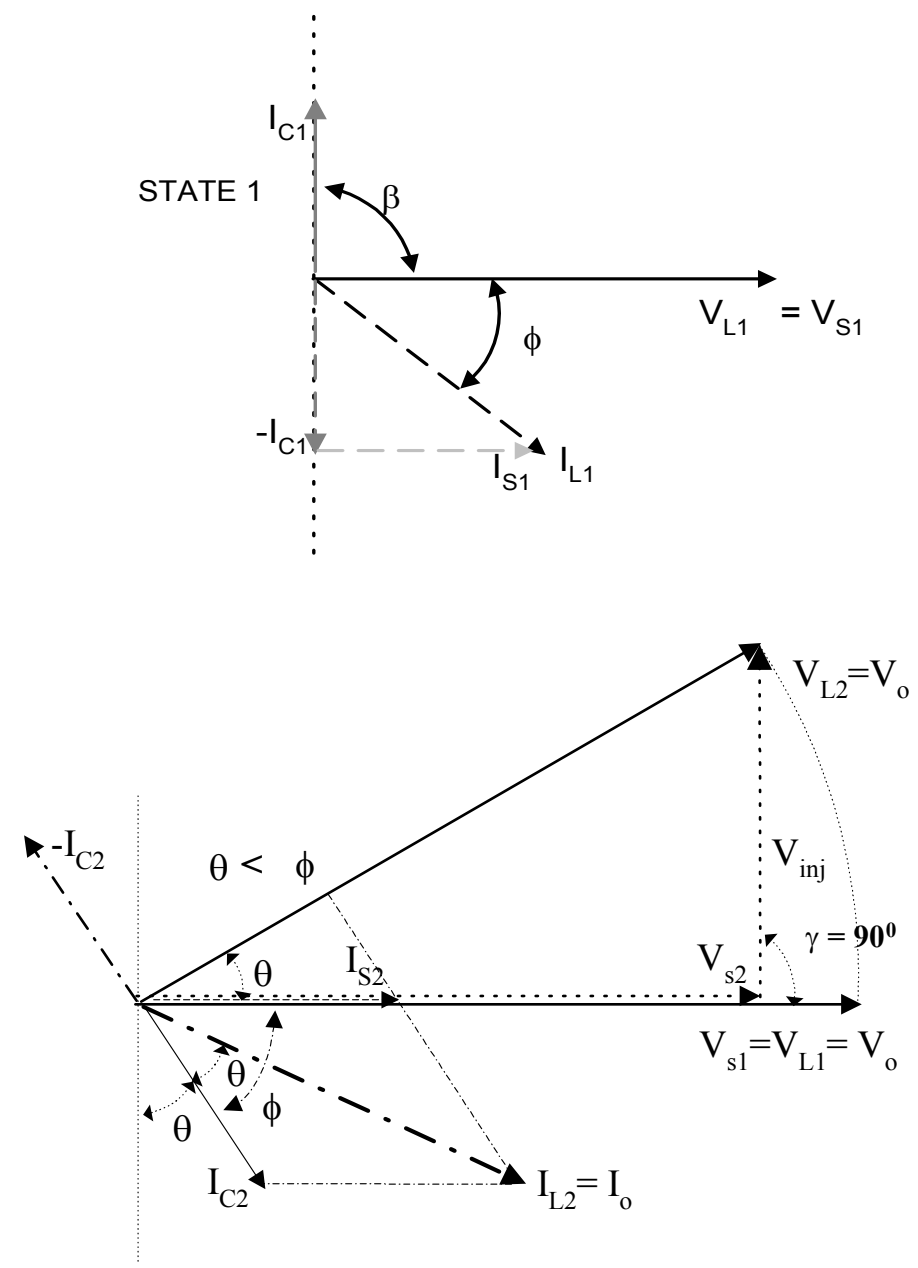

Fig. 2 Phasor diagram of UPQC for fundamental power frequency, when $\theta<\Phi$

Fig. 2a Describes STATE 1, when the supply voltage equals the desired load voltage

Fig. 2b Describes STATE 2, when the supply voltage sags and UPQC injects $V_{\text {inj }}$ to maintain the load voltage at its desired level 


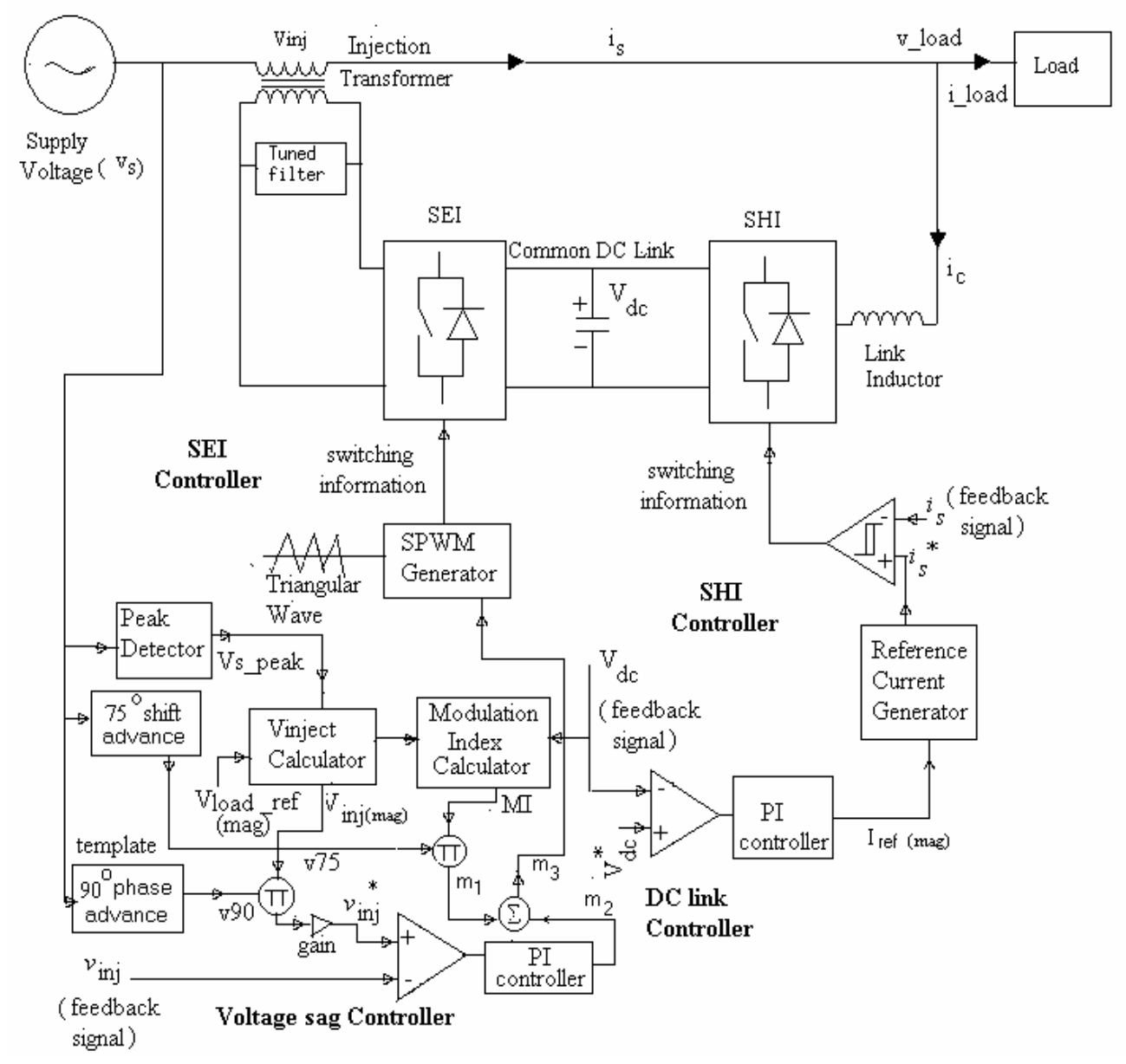

Fig 3 Control block diagram of UPQC-Q 


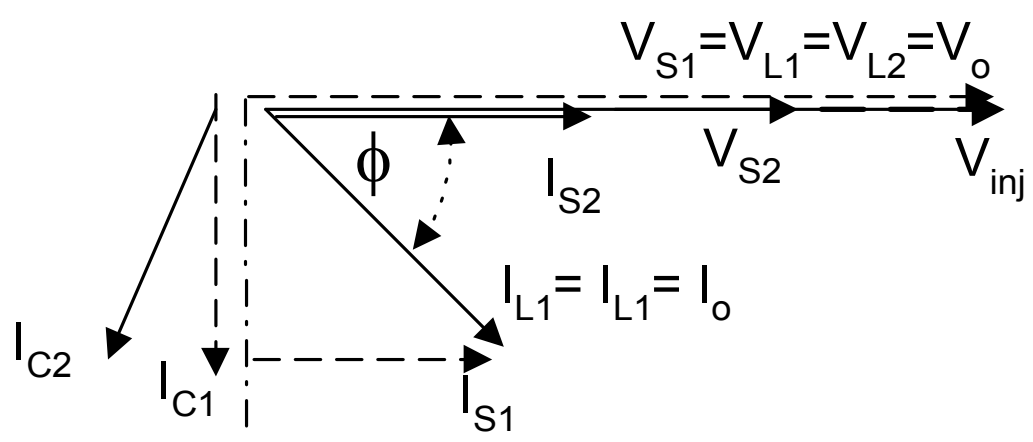

Fig 4 Phasor diagram of UPQC-P 

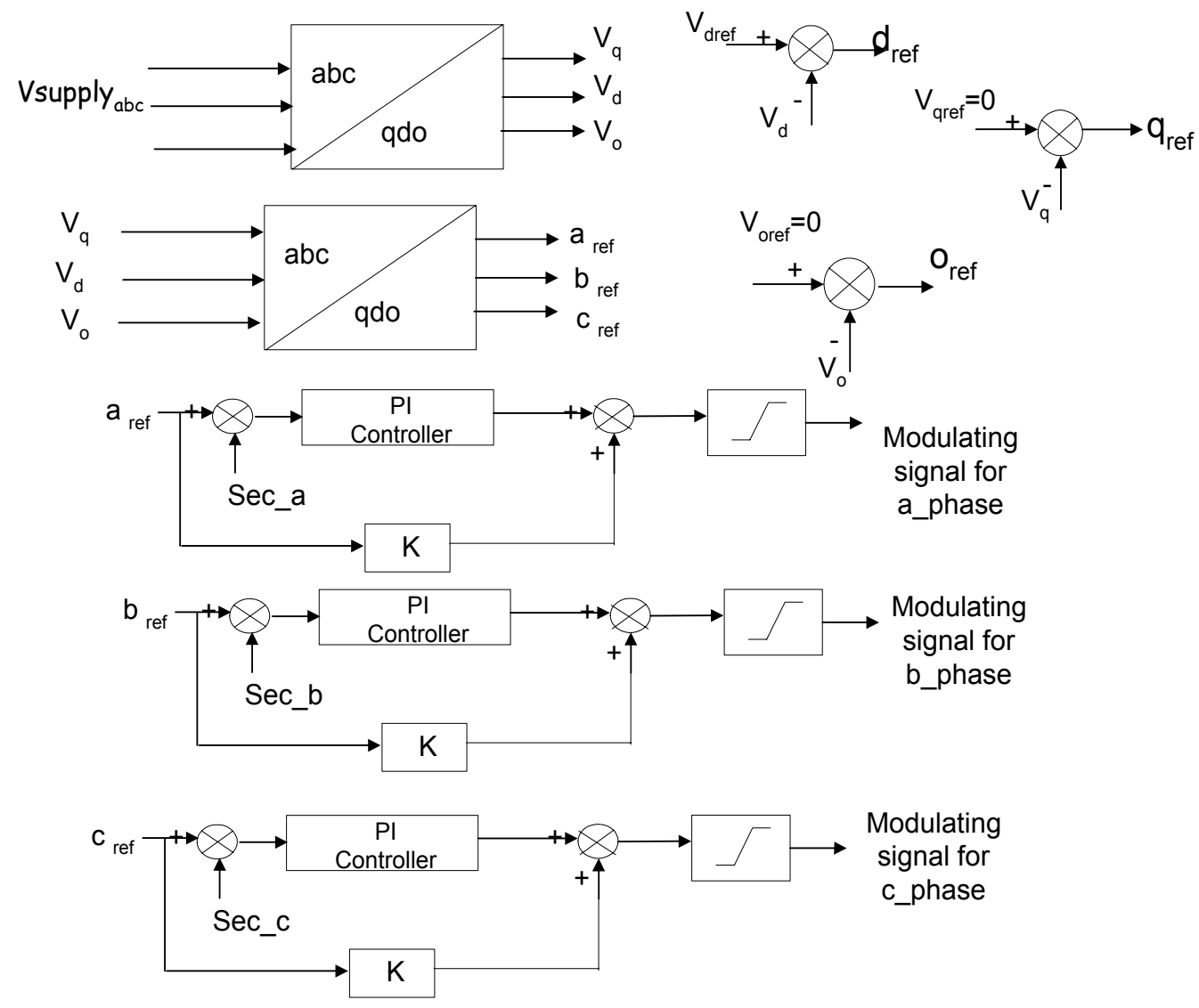

Fig 5 Control block for voltage unbalance compensation in UPQC-P 

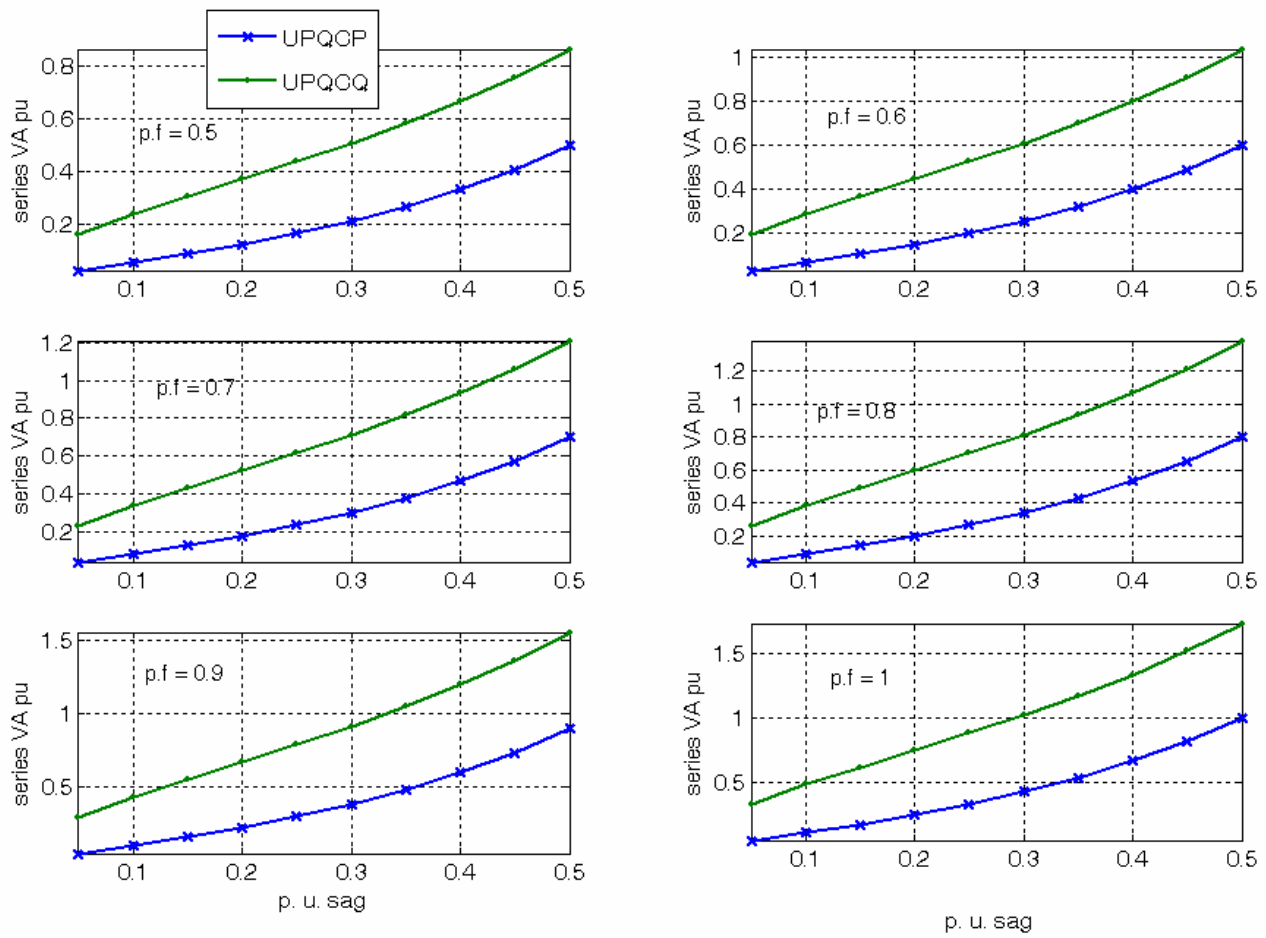

Fig 6 SEI loading of UPQC 

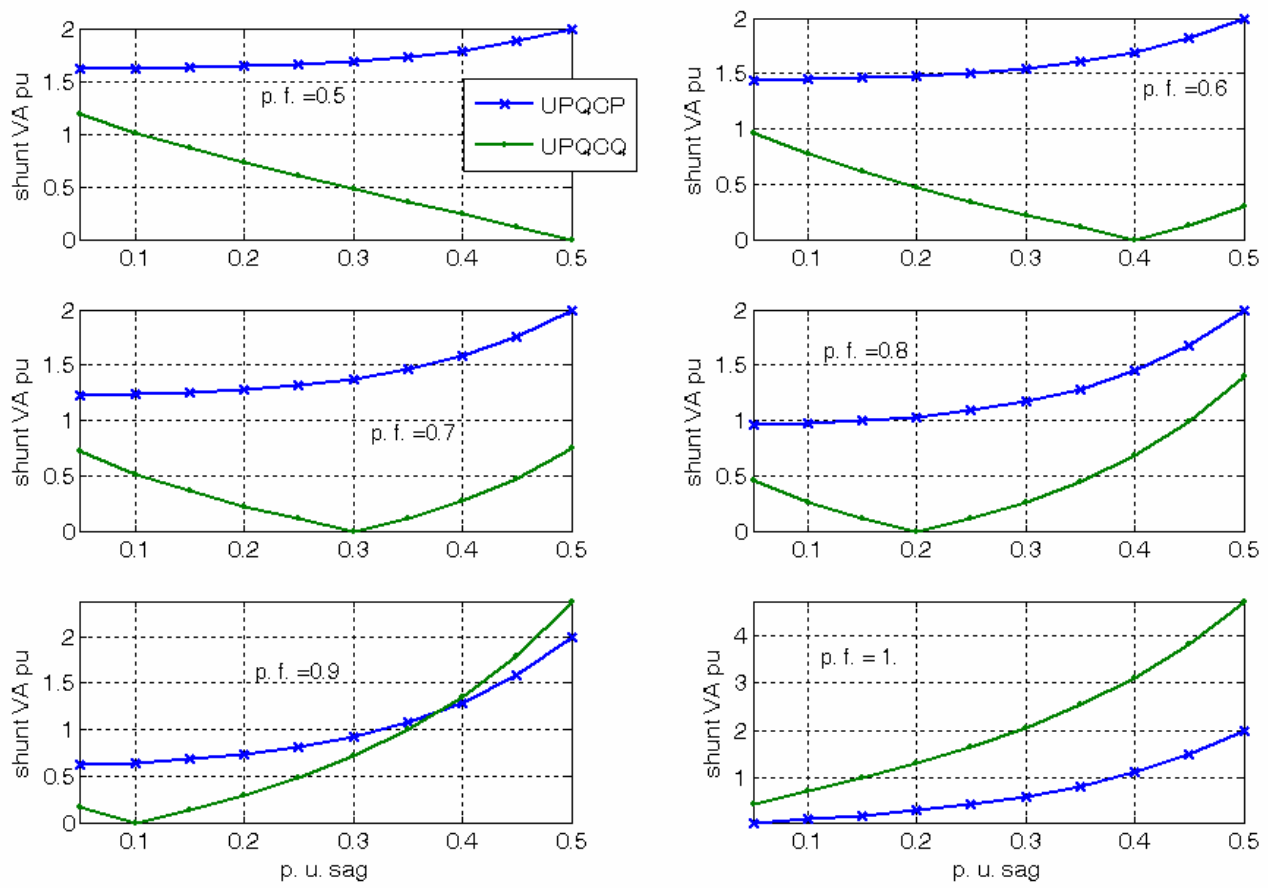

Fig 7 SHI loading of UPQC 

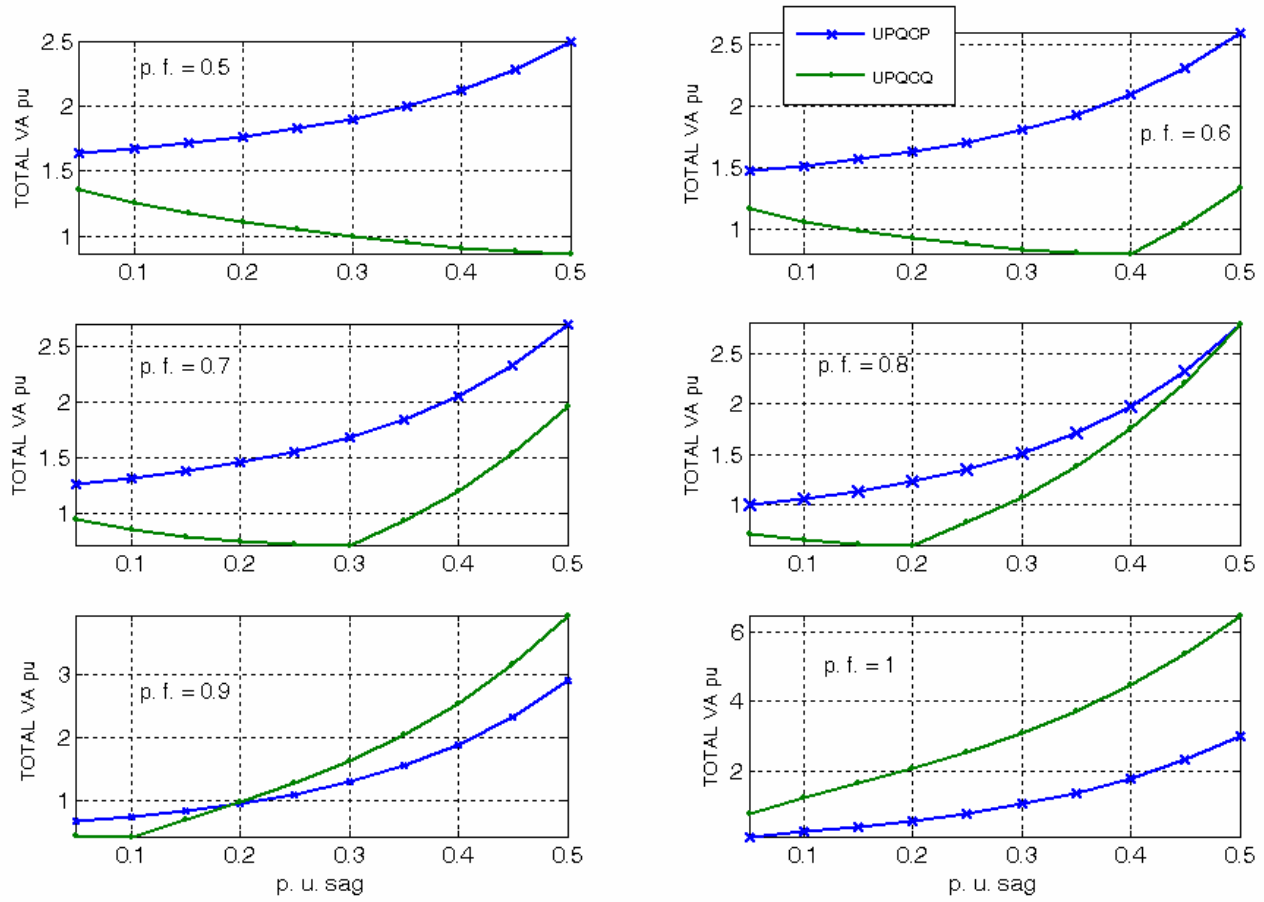

Fig 8 Total VA loading of UPQC 

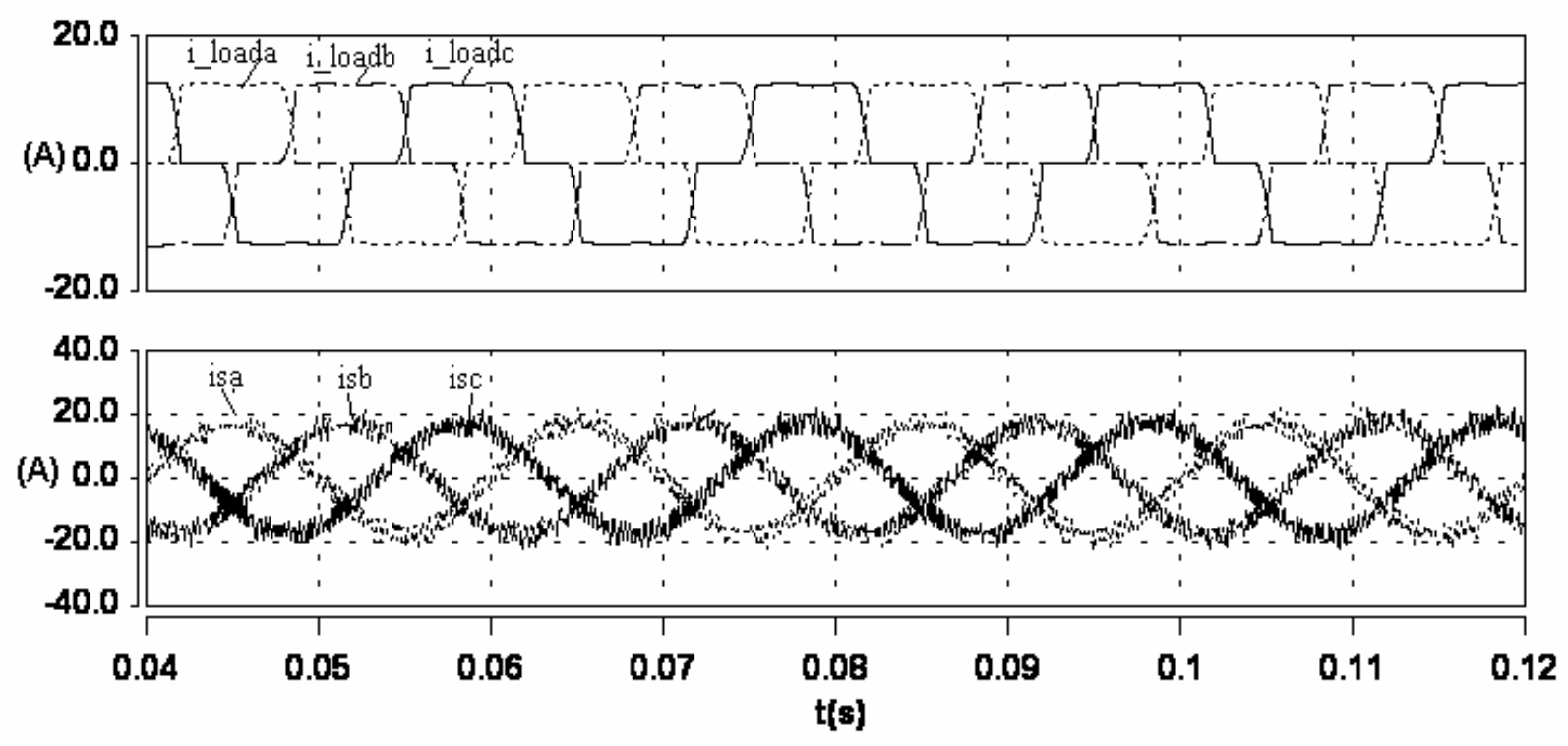

Fig. 9 Three phase load and supply currents 


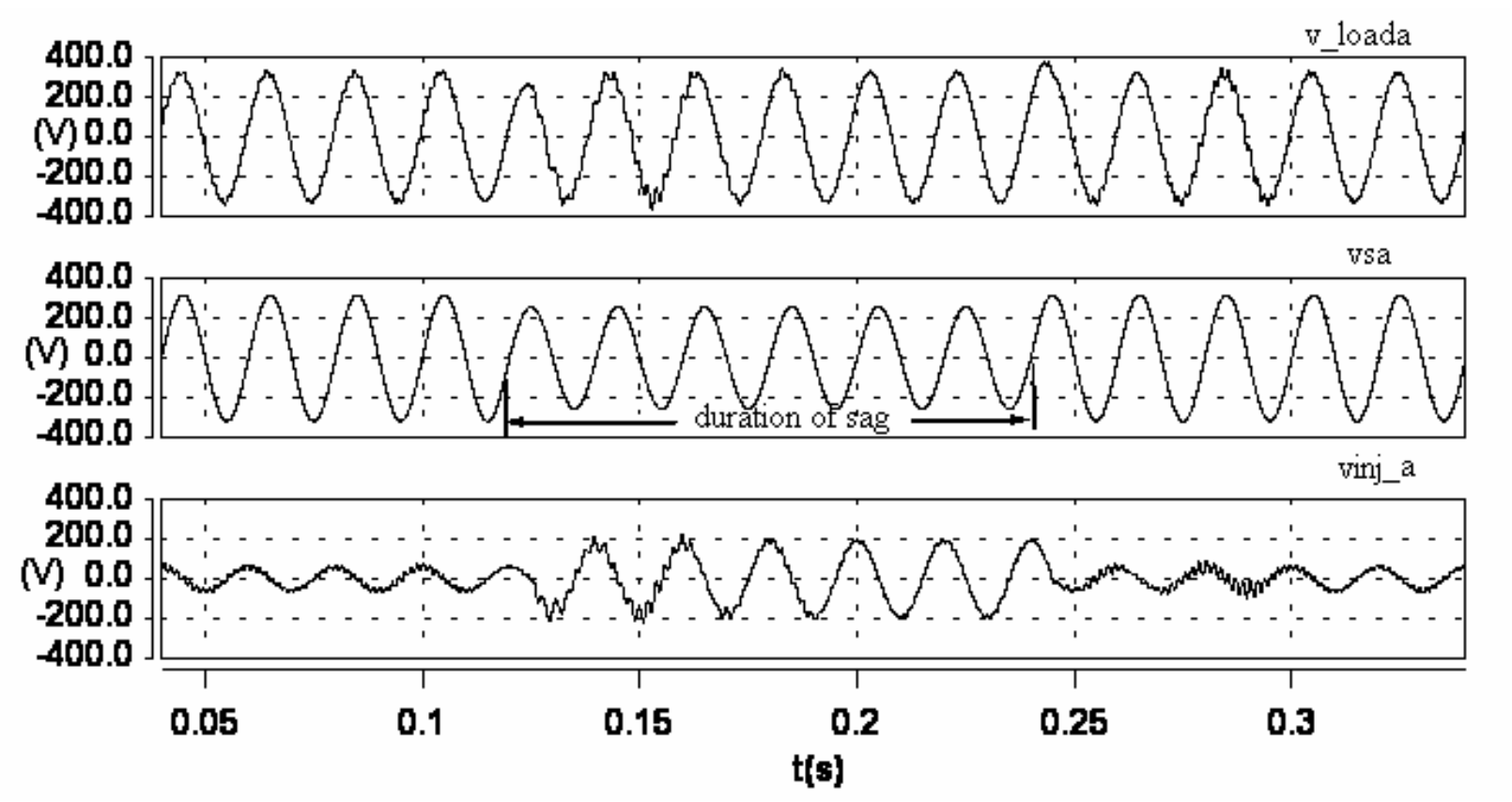

Fig. 10 Load, supply and injected voltages of phase A, under normal and $20 \%$ supply voltage sag condition

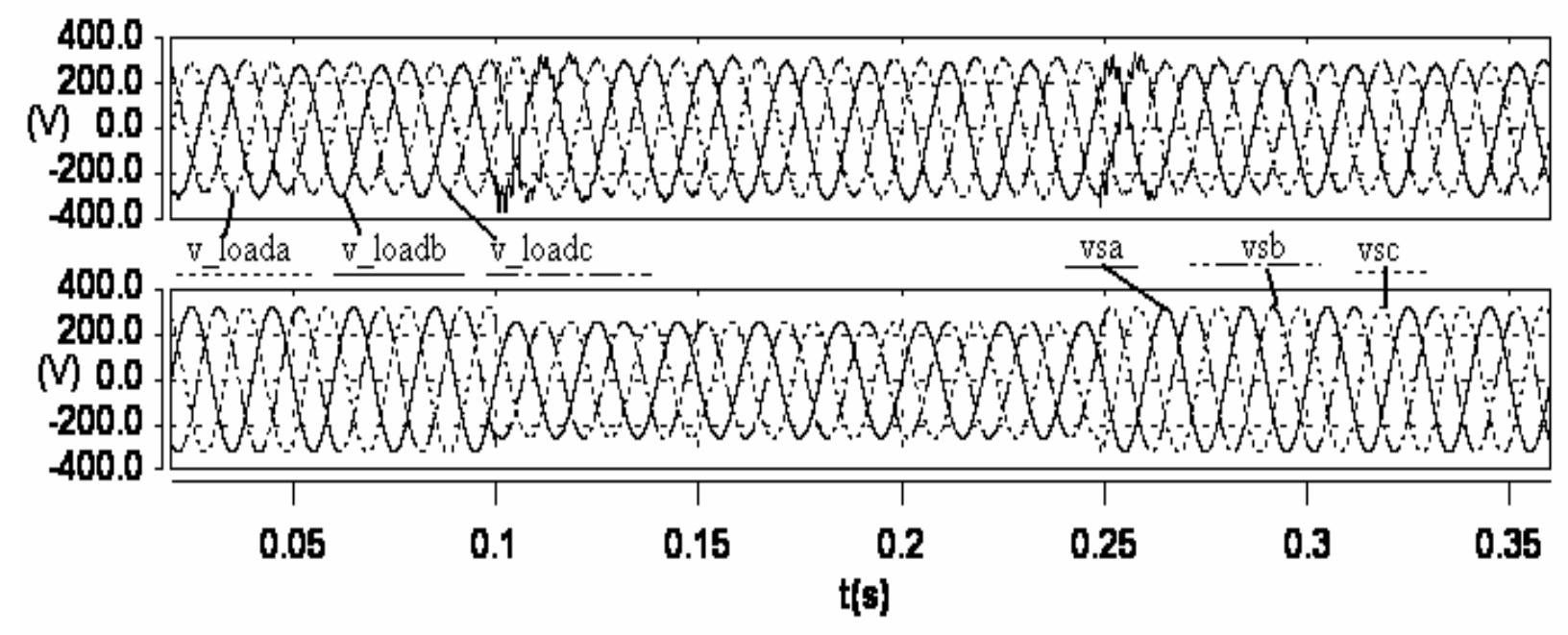

Fig. 11 Load voltage and supply voltage profile under normal and 20\% balanced sag condition 


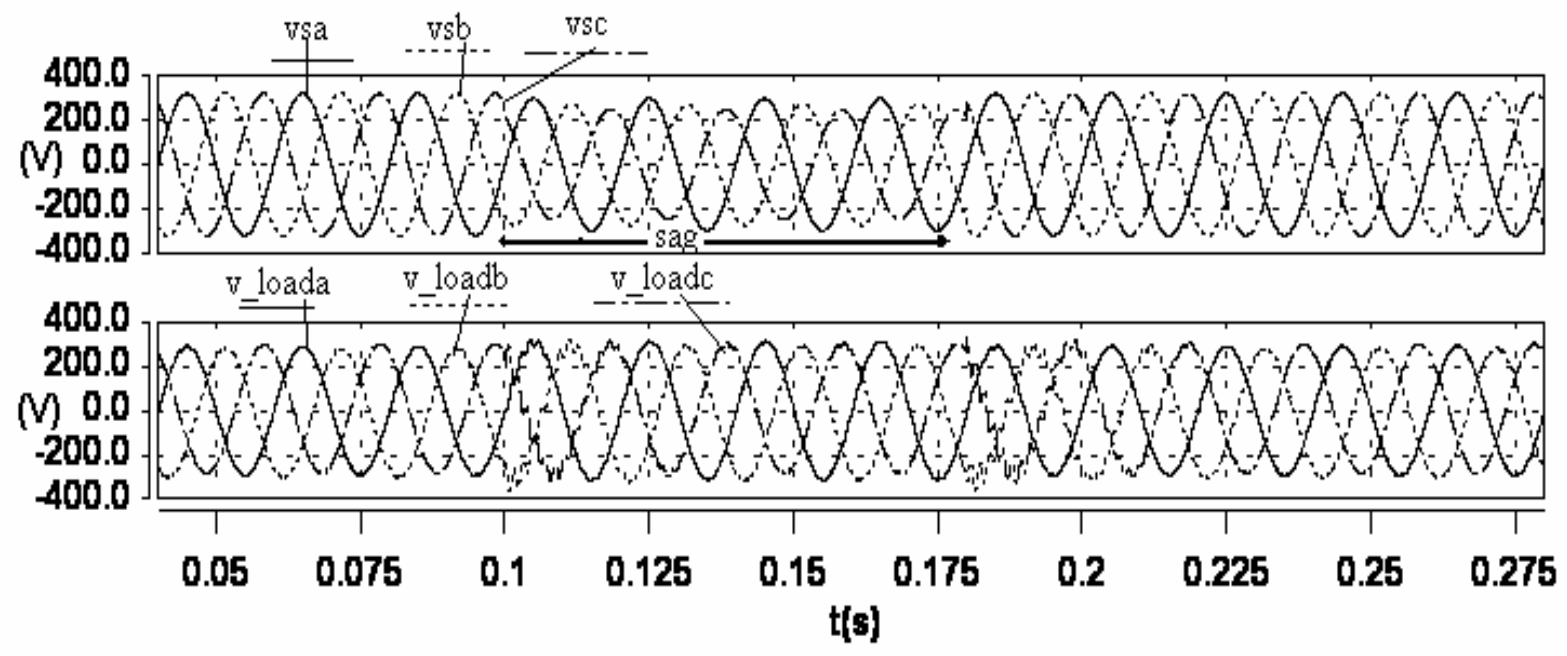

Fig. 12 Load voltage and supply voltage profile under normal and unbalanced sag condition

(V)

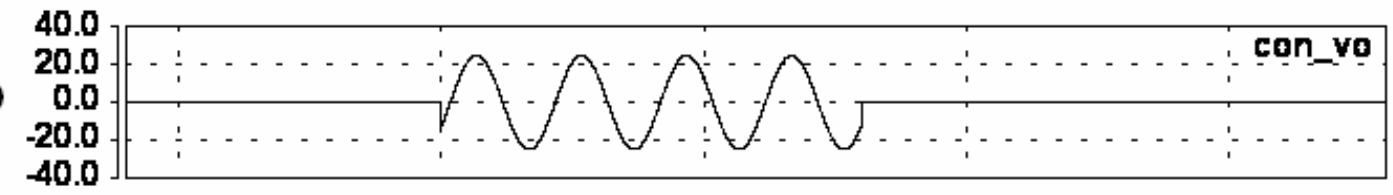

(V)

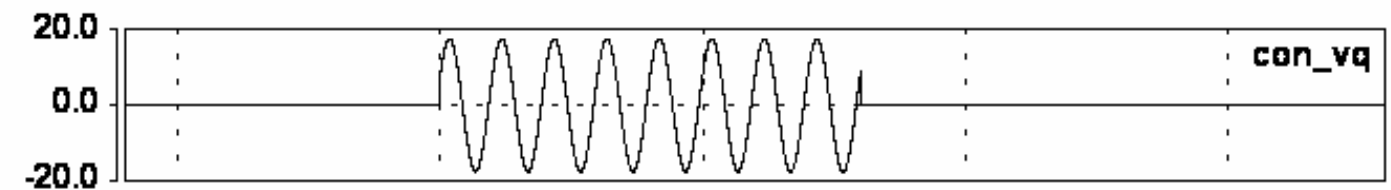

(V)
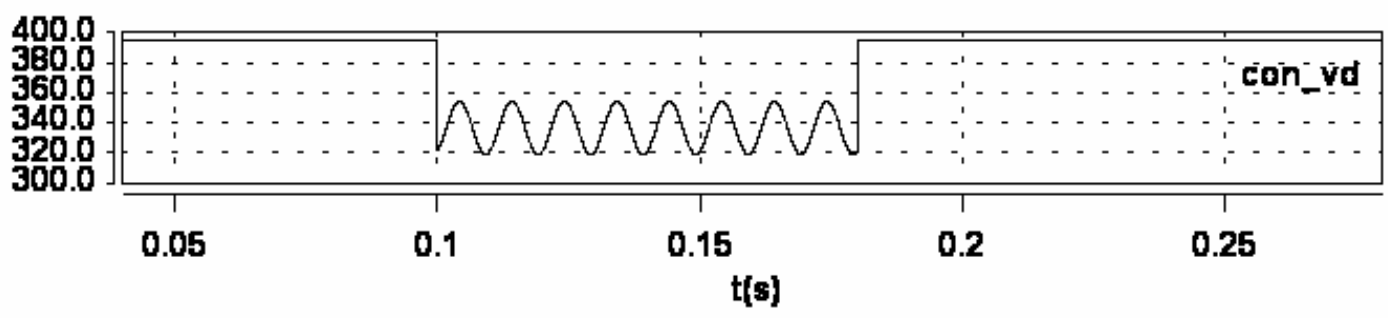

Fig. 13 d- q-o component of voltage under balanced sag condition 